\title{
Usulan kebijakan pencegahan risiko perbankan di era digital
}

\author{
1*Bagaspati Atibrata Cahyolaksono, ${ }^{2}$ Adhitya Mahardhika, dan ${ }^{3}$ M. Ismail Zakaria \\ 1,2,3 Institut Teknologi Sepuluh Nopember, Jl. Teknik Kimia Surabaya 60111 \\ *e-mail korespondensi: bagaspatiatibrata@gmail.com
}

\begin{tabular}{l|l}
\hline \hline \multicolumn{1}{c}{ Keywords } & \multicolumn{1}{c}{ Abstract } \\
\hline \hline $\begin{array}{l}\text { Banking, OJK, } \\
\text { Risk, Risk }\end{array}$ & $\begin{array}{l}\text { This study aims to provide appropriate policy proposals to strengthen the prevention } \\
\text { of banking risks that can be considered by the OJK. Because nowadays, there are } \\
\text { often cases of fraud that occur in banking, which makes customers become hesitant } \\
\text { to choose banks to store their assets. The methodologies used in this study are } \\
\text { literature studies and case studies. The cases used are fraud committed by the head } \\
\text { of Maybank branch that provides losses reaching 20 billion rupiah and fraud of BRI } \\
\text { customers who provide losses reaching 21 billion rupiah. This study shows two types } \\
\text { of risks that arise in these two cases, namely operational risk and reputational risk. } \\
\text { This study also produced some policy suggestions that can be considered for policy } \\
\text { makers (OJK) to prevent similar fraud from happened again. }\end{array}$ \\
\hline
\end{tabular}

Kata Kunci

Abstrak

Perbankan, OJK, Risiko, Manajemen Risiko

\begin{abstract}
Penelitian ini bertujuan untuk memberikan usulan kebijakan yang tepat guna memperkuat pencegahan risiko perbankan yang dapat dipertimbangkan oleh OJK. Pasalnya, saat ini sering terjadi kasus penipuan yang terjadi di perbankan, yang membuat nasabah menjadi ragu-ragu untuk memilih bank untuk menyimpan asetnya. Metodologi yang digunakan dalam penelitian ini adalah studi literatur dan studi kasus. Kasus yang digunakan adalah fraud yang dilakukan oleh pimpinan cabang Maybank yang memberikan kerugian mencapai 20 miliar rupiah dan fraud pada nasabah BRI yang memberikan kerugian mencapai 21 miliar rupiah. Penelitian ini menunjukkan dua jenis risiko yang muncul pada kedua kasus tersebut, yaitu risiko operasional dan risiko reputasi. Kajian ini juga menghasilkan beberapa saran kebijakan yang dapat menjadi pertimbangan bagi pengambil kebijakan (OJK) untuk mencegah terjadinya kecurangan serupa kembali.
\end{abstract}

\section{PENDAHULUAN}

Perkembangan digitalisasi di Indonesia saat ini telah berkembang pesat dari waktu ke waktu dan tak hentinya para pengembangnya terus melakukan inovasi-inovasi berbasis teknologi informasi agar dapat terus meningkatkan pelayanan untuk menyelesaikan aktivitasnya sehari-hari (Prambadi, 2021). Menurut studi yang dilakukan East Ventures Digital Competitiveness Index (EV-DCI) 2021 menunjukkan bahwa daya saing digital antar provinsi di Indonesia saat ini makin merata (Cuaca, 2021). Pemerataan tersebut dapat dilihat dari kenaikan skor median indeks daya saing digital (EV-DCI) yang sebelumnya pada tahun 2020 sebesar 27,9 menjadi 32,1 pada tahun 2021. Terdapat dua faktor utama yang 


\section{Entrepreneurship Bisnis Manajemen Akuntansi (E-BISMA), 2(1), 18-26}

Bagaspati Atibrata Cahyolaksono, Adhitya Mahardhika, dan M. Ismail Zakaria

mendorong Indonesia dalam perkembangan dan pemerataan daya saing digital di Indonesia (Sofyan, 2021).

Pertama, pembangunan infrastruktur di Indonesia yang semakin merata. Infrastruktur merupakan kenaikan skor tertinggi menurut EV-DCI, yakni 7,5 poin menjadi 54,3 pada 2021. Sejumlah indikator yang menopang kenaikan skor ini adalah rasio wilayah yang telah mendapatkan sinyal 3G dan 4G, rasio rumah tangga yang telah memiliki sambungan telepon tetap, serta tingkat gangguan listrik. Kedua, peningkatan pengeluaran untuk teknologi informasi dan komunikasi (TIK) yang mengindikasikan bahwa penduduk Indonesia di seluruh provinsi semakin banyak menggunakan layanan dan transaksi berbasis digital. Kenaikan pada pengeluaran TIK menurut EV-DCI, naik sebesar 6,3 poin di tahun 2021. Hal ini tidak lepas dari pandemi Covid-19 yang memaksa masyarakat untuk menggunakan TIK akibat kebijakan work from home.

Dengan meningkatnya digitalisasi di Indonesia, memaksa berbagai sektor untuk mulai beralih ke digital, tidak terkecuali lembaga jasa keuangan. Menurut Dewi (2020), OJK mengatakan ke depan pihaknya akan terus mendorong digitalisasi lembaga keuangan. Hal ini disebabkan karena digitalisasi sektor keuangan telah menjadi kebutuhan utama masyarakat. Ketua Dewan Komisioner OJK, Wimboh Santoso menegaskan, industri keuangan keuangan juga harus lebih aktif dan cepat dalam beradaptasi dengan perkembangan teknologi digital saat ini. Sebab, di era yang serba cepat jika terlambat memasuki ekosistem digital bisa berujung pada kegagalan bersaing di industri keuangan. Apalagi, dengan adanya pandemi Covid-19 yang mengharuskan masyarakat untuk melakukan transaksi secara digital. Dengan perubahan industri keuangan menjadi digitalisasi, diperlukan penguatan manajemen risiko pada lembaga jasa keuangan (Astutik \& Hastuti, 2020).

Manajemen Risiko didefinisikan sebagai proses identifikasi, penilaian, dan prioritas risiko yang diikuti oleh koordinasi sumber daya, ekonomi untuk meminimalkan, memantau, dan mengawasi kemungkinan terjadinya peristiwa yang dapat merugikan (Hubbard, 2009). Menurut Davis \& Spekman (2004), bahwa risiko adalah kemungkinan dari variasi-variasi yang terkandung di dalam hasil yang diharapkan dengan menyiratkan keberadaan suatu ketidakpastian. Selanjutnya, ketidakpastian dapat didefinisikan sebagai penentu utama dari risiko yang mungkin tidak dapat dihilangkan sepenuhnya, tetapi dapat dilakukan mitigasi dengan langkah-langkah pengelolaan risiko (Lewis \& Slack, 2001).

Bank, yang menurut Undang-Undang RI No. 10 Tahun 1998 tentang Perbankan sebagai badan usaha yang menghimpun dana dari masyarakat dan menyalurkannya kepada masyarakat dalam bentuk kredit atau lainnya, memerlukan penanganan manajemen risiko yang tepat. Hal ini disebabkan bank menjadi rawan terhadap tindak kejahatan, baik dari internal maupun eksternal bank itu sendiri, mengingat fungsi bank yang menghimpun dana masyarakat banyak. Oleh sebab itu, penguatan manajemen risiko terhadap tindak kejahatan yang bisa terjadi dalam perbankan. Salah satu cara penguatan yang dapat dilakukan adalah dengan memanfaatkan teknologi yang telah berkembang saat ini. Karena, dengan berkembangnya teknologi yang semakin pesat, semua organisasi harus beradaptasi terhadap perkembangan tersebut. 


\section{Entrepreneurship Bisnis Manajemen Akuntansi (E-BISMA), 2(1), 18-26}

Bagaspati Atibrata Cahyolaksono, Adhitya Mahardhika, dan M. Ismail Zakaria

Studi ini bertujuan untuk melakukan identifikasi jenis risiko yang dapat muncul dalam kasus yang terjadi dalam perbankan dengan menggunakan dua studi kasus, yaitu kasus Maybank dan BRI. Selain itu, penelitian ini juga bertujuan untuk memberikan rekomendasi kebijakan kepada regulator agar risiko yang serupa dapat dicegah dengan lebih baik lagi.

\section{KAJIAN TEORI}

\section{Bank}

Menurut Undang-Undang RI No. 11 Tahun 1998 tentang Perbankan, Bank dapat didefinisikan sebagai bentuk badan usaha yang berfungsi untuk menghimpun dana dari masyarakat dalam bentuk simpanan dan menyalurkannya kepada masyarakat dalam bentuk kredit dan/atau bentuk-bentuk lainnya dalam rangka meningkatkan taraf hidup rakyat banyak. Fungsi utama perbankan Indonesia adalah sebagai penghimpun dan penyalur dana masyarakat. perbankan Indonesia bertujuan menunjang pelaksanaan pembangunan nasional dalam rangka meningkatkan pemerataan, pertumbuhan ekonomi, dan stabilitas nasional ke arah peningkatan kesejahteraan rakyat banyak.

\section{Manajemen Risiko}

Risiko adalah kejadian yang mungkin dapat terjadi di masa yang akan datang dan bila terjadi akan berdampak buruk pada suatu objek, dimana tidak semua risiko bisa terjadi maupun dapat diketahui dengan pasti dampak dari risiko yang telah terjadi, maka dari itu diperlukan pengelolaan risiko yang lebih efektif. Menurut Tummala \& Schoenherr (2011) perusahaan perlu mengidentifikasi risiko yang potensial, jumlah kemungkinan risiko dapat terjadi, konsekuensi, serta dampak dari risiko-risiko tersebut sehingga dapat membentuk perencanaan aksi untuk mengelola risiko-risiko tersebut.

Menurut Peraturan Nomor 11/25/PBI/2010 mengenai Perubahan atas PBI Nomor 5/8/PBI/2003 yang mengatur tentang Penerapan Manajemen Risiko, Risiko didefinisikan sebagai potensi kerugian yang disebabkan oleh terjadinya suatu peristiwa (events) tertentu. Sedangkan, manajemen risiko adalah serangkaian metodologi dan prosedur yang tertruktur untuk mengidentifikasi, mengukur, memantau dan mengendalikan risiko yang dapat timbul dari seluruh kegiatan usaha bank (Napitupulu, 2020).

\section{Klasifikasi Risiko dalam Perbankan}

Menurut Bank Indonesia melalui Peraturan Bank Indonesia No. 11/25/PBI/2010 tentang Penerapan Manajemen Risiko bagi Bank Umum per 1 Juli 2010 membagi risiko keuangan dalam kelompok sebagai sebagai berikut:

- Risiko kredit, adalah risiko akibat kegagalan debitur dan atau pihak lain dalam memenuhi kewajiban kepada Bank. Termasuk dalam risiko kredit adalah risiko konsentrasi kredit. Risiko konsentrasi kredit merupakan risiko yang timbul akibat terkonsentrasinya penyediaan dana kepada 1 (satu) pihak atau sekelompok pihak, industri, sektor, dan atau area geografis tertentu yang berpotensi menimbulkan kerugian cukup besar yang dapat mengancam kelangsungan usaha Bank. 


\section{Entrepreneurship Bisnis Manajemen Akuntansi (E-BISMA), 2(1), 18-26 \\ Bagaspati Atibrata Cahyolaksono, Adhitya Mahardhika, dan M. Ismail Zakaria}

- Risiko pasar, adalah risiko pada posisi neraca dan rekening administratif termasuk transaksi derivatif, akibat perubahan secara keseluruhan dari kondisi pasar, termasuk risiko perubahan harga option.

- Risiko likuiditas, adalah risiko akibat ketidakmampuan Bank untuk memenuhi kewajiban yang jatuh tempo dari sumber pendanaan arus kas dan atau dari aset likuid berkualitas tinggi yang dapat diagunkan, tanpa mengganggu aktivitas dan kondisi keuangan Bank.

- Risiko operasional, adalah risiko akibat ketidakcukupan dan atau tidak berfungsinya proses internal, kesalahan manusia, kegagalan sistem, dan atau adanya kejadian-kejadian eksternal yang mempengaruhi operasional Bank.

- Risiko hukum, adalah risiko akibat tuntutan hukum dan atau kelemahan aspek yuridis.

- Risiko strategis, adalah risiko akibat ketidaktepatan dalam pengambilan dan/atau pelaksanaan suatu keputusan stratejik serta kegagalan dalam mengantisipasi perubahan lingkungan bisnis.

- Risiko reputasi, adalah risiko akibat menurunnya tingkat kepercayaan stakeholder maupun pihak eksternal, yang bersumber dari persepsi negatif terhadap Bank.

Risiko kepatuhan, adalah risiko akibat Bank tidak mematuhi dan atau tidak melaksanakan peraturan perundang-undangan dan ketentuan yang berlaku.

\section{METODE PENELITIAN}

Metodologi yang digunakan adalah metode studi literature dan studi kasus. Metode studi literatur adalah serangkaian kegiatan yang berkenaan dengan metode pengumpulan data pustaka, membaca dan mencatat, serta mengelola data tersebut sebagai bahan penelitian. Sedangkan metode studi kasus adalah metode yang dilakukan dengan mempelajari individu, organisasi, peristiwa, atau tindakan, yang ada di waktu dan tempat tertentu secara nyata.

Penelitian akan dimulai dengan membahas kasus dua kasus yang menjadi bahan penelitian. Setelah membahas kasus tersebut, kemudian akan dilakukan pengidentifikasian pada masing-masing kasus mengenai jenis risiko yang muncul. Setelah mengetahui jenis risiko yang muncul, selanjutnya akan diidentifikasi penyebab risiko tersebut dapat muncul. Selanjutnya, penelitian akan memberikan saran kebijakan yang dapat menjadi dipertimbangkan untuk regulator (OJK) sebagai upaya untuk mencegah risiko yang serupa dapat muncul kembali (Kencana, 2021).

\section{HASIL DAN PEMBAHASAN}

\section{Kasus Penipuan Maybank}

Kasus penipuan yang dilakukan oleh Kepala Cabang Maybank Cipulir kepada seorang atlit e-sport bernama Winda Earl yang memberikan dampak kerugian senilai 20 miliar rupiah. Dilansir dari Kompas (Idris, 2020), Kasus ini bermula ketika korban di tawari oleh pelaku yang menjabat sebagai kepala cabang di Maybank Cipulir. Korban ditawari untuk 


\section{Entrepreneurship Bisnis Manajemen Akuntansi (E-BISMA), 2(1), 18-26}

Bagaspati Atibrata Cahyolaksono, Adhitya Mahardhika, dan M. Ismail Zakaria

membuka simpanan berupa rekening berjangka dengan bunga simpanan yang tinggi dibanding produk simpanan bank yang dikeluarkan pada umumnya. Tawaran tersebut membuat korban tertarik dan segera menyetorkan uang senilai 20 miliar rupiah.

Ternyata, pelaku tidak benar-benar membuat rekening berjangka sesuai yang dijanjikannya di Maybank. pelaku memalsukan semua data-data untuk membuat korban percaya bahwa dirinya sudah dibuatkan rekening berjangka di bank tersebut. Uang milik korban selanjutnya ditarik tanpa sepengetahuan dan izin dari korban. Pelaku kemudian mentransfer uang korban ke rekan-rekan lainnya, kemudian diputar dengan harapan bisa mendapatkan keuntungan.

Dari kasus penipuan yang dilakukan kepala cabang Maybank Cipulir, terdapat dua jenis risiko yang muncul, yaitu risiko operasional dan risiko reputasi. Risiko operasional yang muncul adalah risiko kesalahan manusia, dimana pelaku yang merupakan oknum internal bank melakukan penyalahgunaan kekuasaan yang berakibat kepada kerugian bagi korban.

Risiko selanjutnya adalah risiko reputasi. Oknum yang merupakan kepala cabang, seharusnya memberikan rasa aman kepada nasabahnya, namun yang terjadi adalah oknum tersebut yang menghilangkan rasa aman tersebut. Sehingga, dengan kejadian ini sangat berpengaruh terhadap reputsi Maybank kedepannya.

\section{Penyebab Munculnya Risiko}

Ada beberapa alasan mengapa risiko ini dapat muncul, alasan yang pertama adalah peraturan yang masih kurang lengkap mengenai pengendalian internal bank. OJK sebagai lembaga yang berwenang dalam mengatur dan mengawasi lembaga jasa keuangan belum memiliki peraturan yang tepat dalam mengatur pengawasan pegawai internal perusahaan. Selain itu, OJK akan melakukan tindakan pada pelanggaran yang dilakukan jika ada laporan atau keluhan dari korban. OJK hanya melakukan tindakan secara mandiri pada pelanggaran yang berasal dari data sekunder (laporan keuangan, dan lain-lain). Sehingga pelanggaran yang dilakukan oleh oknum Maybank ini masih terjadi di banyak kasus yang menyangkut bank (Supriyatna \& Fauzi, 2020).

Sedangkan, risiko reputasi muncul akibat risiko operasional terjadi. Reputasi didapatkan dari kinerja Bank selama beroperasi. Jika selama beroperasi terdapat pelanggaran, maka bank dapat kehilangan rasa kepercayaan nasabah. Hal ini disebabkan karena bank yang seharusnya solusi aman dalam menyimpan uangnya, justru menjadi tempat yang tidak aman untuk menyimpan uang nasabah.

\section{Pencegahan terhadap Risiko}

OJK bisa membuat kebijakan yang mengharuskan semua karyawan bank, tidak terkecuali untuk mengisi laporan terkait apa yang dilakukan kayawan tersebut. Laporan bisa memanfaatkan teknologi yang berkembang, misal OJK membuat database terintegrasi yang berfungsi menyimpan laporan tersebut. Laporan tersebut dilaporkan secara berkala, misal satu minggu sekali. Laporan yang harus dilaporkan adalah transaksi perbankan yang dilakukan serta logbook kegiatan yang dilakukan karyawan selama periode tersebut. Selain itu, OJK juga dapat melakukan pengawasan pada rekening pribadi milik karyawan. Hal ini diperlukan agar OJK dapat melihat adanya transaksi tidak wajar yang masuk ke rekening 


\section{Entrepreneurship Bisnis Manajemen Akuntansi (E-BISMA), 2(1), 18-26}

Bagaspati Atibrata Cahyolaksono, Adhitya Mahardhika, dan M. Ismail Zakaria

pribadi milik karyawan, dan bisa langsung melakukan klarifikasi kepada yang bersangkutan. Sehingga, OJK bisa menindaklanjuti jika transaksi tersebut terbukti terjadi pelanggaran.

\section{Kasus Penipuan Nasabah BRI}

Kasus penipuan yang dilakukan oleh sindikat terhadap 3000 nasabah BRI dengan kerugian ditaksir mencapai 21 miliar rupiah. Menurut Napitupulu (2020), Kasus ini dimulai dari sindikat yang berpura - pura menjadi pihak bank untuk menghubungi nasabah, sindikat berupaya untuk mendapatkan One Time Password (OTP) milik nasabah yang dikirimkan oleh pihak bank. OTP ini didapatkan ketika pembukaan rekening oleh perbankan yang bertujuan untuk konfirmasi. Setelah berhasil mendapatkan OTP, para sindikat dengan leluasa bisa membobol akun rekening tersebut dan menguras isi saldo milik nasabah. Para sindikat ini juga membuat rekening penampungan dengan memanfaatkan warga kampung sekitar yang bertujuan untuk menampung uang hasil penipuan.

Dari kasus penipuan yang dilakukan sindikat terhadap 3000 Nasabah BRI, terdapat dua jenis risiko yang muncul, yaitu risiko operasional dan risiko reputasi. Risiko operasional yang muncul adalah risiko kesalahan manusia dan kegagalan sistem, dimana kesalahan nasabah tertipu dengan kedok pelaku yang berpura - pura menjadi pihak bank dengan memberikan OTP, dilain sisi kegagalan sistem BRI tidak dapat menanggulangi untuk mengantisipasi para pelaku yang berkedok sebagai pihak bank. Sehingga menyebabkan hilangnya uang nasabah yang ditaksir mencapai 21 miliar rupiah.

\section{Penyebab Munculnya Risiko}

Ada beberapa alasan mengapa risiko ini dapat muncul, alasan yang pertama adalah nasabah kurang berhati - hati dalam menjaga kerahasiaan OTP, apabila pihak pelaku menelfon menggunakan nomer biasa dan mengatasnamakan BRI maka perlu ada penjelasan saat pembukaan rekening oleh pihak bank untuk mengantisipasi hal dan kegagalan sistem bank yang tidak dapat mengantisipasi para pelaku yang berkedok sebagai pihak bank karena dari pihak bank tidak melakukan kerjasama dengan pihak penyedia layanan seluler seperti Telkomsel, XL, Indosat dll. Apabila pihak bank telah bekerjasama dengan pada penyedia layanan seluler, apabila pelaku menggunakan nomer dengan nama BRI maka dari pihak penyedia seluler akan mampu mendeteksi bahwa nomer yang digunakan oleh pelaku telah dirancang sedemikian rupa dengan nama BRI agar korban terkecoh, yang nantinya bisa ditindaklanjuti oleh pihak penyedia layanan akan berkoordinasi ke BRI dan Penegak Hukum.

Sedangkan, risiko reputasi muncul akibat risiko operasional terjadi. Reputasi didapatkan dari kinerja Bank selama beroperasi. Jika selama beroperasi terdapat pelanggaran, maka bank dapat kehilangan rasa kepercayaan nasabah. Hal ini disebabkan karena bank yang seharusnya solusi aman dalam menyimpan uangnya, justru menjadi tempat yang tidak aman untuk menyimpan uang nasabah. 


\section{Entrepreneurship Bisnis Manajemen Akuntansi (E-BISMA), 2(1), 18-26 \\ Bagaspati Atibrata Cahyolaksono, Adhitya Mahardhika, dan M. Ismail Zakaria}

\section{Pencegahan Terhadap Risiko}

Terdapat beberapa usulan untuk mencegah kasus seperti BRI dapat di minimalisir:

- Perlu adanya pembinaan terhadap nasabah disaat membuka tabungan baru tentang modus - modus penipuan.

- Perlu adanya kerjasama antara Bank dengan penyedia layanan seluler yang bertujuan agar pihak penyedia layanan seluler dapat mengetahui apakah nomor yang digunakan official milik bank atau ada oknum yang menggunakan nomor seperti official milik bank, disini pihak penyedia layanan bisa berkoordinasi dengan penegak hukum untuk memprosesnya.

- Perlu adanya sistem keamanan lebih didalam internet banking, pertama Uji Keontektikan hingga saat ini hanya memasukkan PIN saat login, agar tingkat keamaan lebih ketat bisa ditambahkan akses nama orang tua atau hobi untuk login internet banking. Kedua saat proses transaksi transfer uang atau pembayaran perlu dilakukan dengan memasukkan PIN, agar tingkat keamanan lebih ketat bisa ditambahkan dengan persetujuan transfer melalui email atau sms nasabah.

Perlu adanya kerjasama antara Bank dengan Bank yang lain untuk mempermudah proses keterbukaan informasi rekening pelaku, dikarenakan proses keterbukaan informasi yang dimulai dari pembuatan laporan kehilangan, laporan polisi, persetujuan bank pelapor, dan investasi informasi pelaku di bank yang bersangkutan. Ini akan memakan waktu yang sangat lama dan akan berakibat uang dari korban bisa berpindah lagi ke bank lain serta risiko paling buruknya uangnya akan habis dipakai pelak

\section{KESIMPULAN DAN SARAN}

Terdapat beberapa kesimpulan yang dapat diambil dari studi ini. Beberapa kesimpulan tersebut diantaranya adalah:

- Terdapat dua kasus yang digunakan dalam karya riset ilmiah ini. Kasus pertama adalah kasus penipuan yang dilakukan oleh oknum kepala cabang Maybank Cipulir yang memberikan kerugian mencapai 20 miliar rupiah. Kasus kedua adalah kasus penipuan yang dilakukan suatu sindikat kepada nasabah BRI yang memberikan dampak kerugian mencapai 21 miliar rupiah. Kedua kasus tersebut dapat disimpulkan bahwa sistem control terhadap transaksi perbankan masih lemah dan dapat dimanipulasi oleh oknum perbankan yang mengerti sistem didalamnya maupun oknum diluar perbankan yang dapat melihat celah bahwa sistem otorisasi saat ini masih belum dapat mencegah terjadinya penipuan.

- Dari analisis yang dilakukan pada kedua kasus tersebut, terdapat dua jenis risiko yang muncul yaitu risiko operasional dan risiko reputasi. Kedua resiko tersebut dihadapi dunia perbankan di Indonesia setiap tindakan yang dilakukan oleh oknumoknum dalam kedua kasus terjadi berulang di masa mendatang. Pengawasan secara teratur dan berkala dalam setiap transaksi perbankan kurang diterapkan dalam penerapan pengelolaan manajemen resiko. 


\section{Entrepreneurship Bisnis Manajemen Akuntansi (E-BISMA), 2(1), 18-26 \\ Bagaspati Atibrata Cahyolaksono, Adhitya Mahardhika, dan M. Ismail Zakaria}

Selain kesimpulan, terdapat beberapa saran yang dapat diambil studi ini. Beberapa saran tersebut diantaranya:

- Dalam studi kasus Maybank, OJK sebagai regulator dan pengawas perbankan dapat membuat kebijakan yang mengharuskan semua karyawan bank, tidak terkecuali untuk mengisi laporan terkait apa yang dilakukan kayawan tersebut. Laporan bisa memanfaatkan teknologi yang berkembang, misal OJK membuat database terintegrasi yang berfungsi menyimpan laporan tersebut. Laporan tersebut dilaporkan secara berkala, misal satu minggu sekali.

Untuk studi kasus BRI, terdapat beberapa saran, diantaranya adalah perlu adanya sosialisasi terhadap nasabah disaat membuka tabungan baru tentang modus - modus penipuan. Selain itu, perlu adanya perbaikan pada sistem keamanan internet banking, seperti penyempurnaan uji keontentikan agar akses semakin eksklusif hanya milik nasabah.

\section{DAFTAR PUSTAKA}

Astutik, Y., \& Hastuti, R.K. (2020). Ada Tantangan Keamanan, Digital Banking Tetap Melesat. Tersedia di https://www.cnbcindonesia.com/tech/20200824171851-37181615/ada-tantangan-keamanan-digital-banking-tetap-melesat. Diakses pada April 2021.

Bank Indonesia. Peraturan Bank Indonesia tentang Penerapan Manajemen Risiko bagi Bank Umum. PBI No. 5/8/PBI/2003

Bank Indonesia. Peraturan Bank Indonesia tentang Penerapan Manajemen Risiko bagi Bank Umum. PBI No. 11/25/PBI/2010

Cuaca, Willson (2021). Pandemic accelerated digital transformation in Indonesia, making it more equal. Tersedia di https://east.vc/east-ventures/digital-competitivenessindonesia-ev-dci-2021/. Diakses pada Maret 2021.

Davis, E. W., \& Spekman, R. E. (2004). Risky business: expanding the discussion on risk and the extended enterprise. International Journal of Physical Distribution and Logistics Management, 34 (5), 414-433.

Dewi, L.M.S.S. (2020). OJK imbau industri keuangan untuk segera bertransformasi ke digital. Tersedia di https://keuangan.kontan.co.id/news/ojk-imbau-industri-keuanganuntuk-segera-bertransformasi-ke-digital. Diakses pada April 2021.

Gustini, D. W., \& Afriani, S. (2014). Analisis Manajemen Risiko Pada Kantor Pusat PT. Bank Bengkulu. EKOMBIS REVIEW: Jurnal Ilmiah Ekonomi dan Bisnis, 2(1), 105121.

Hubbard, D. W. (2009). The Failure of Risk Management; Why Its Broken and How to Fix It. Hoboken. New Jersey: John Willey \& Sons, Inc.

Idris, Muhammad (2020). Kronologi Lengkap Raibnya Tabungan Rp 20 Miliar Winda Earl di Maybank. Tersedia di https://money.kompas.com/read/2020/11/09/130201026/ kronologi-lengkap-raibnya-tabungan-rp-20-miliar-winda-earl-dimaybank?page=all\#: :text=JAKARTA $\% 2 \mathrm{C} \% 20 \mathrm{KOMPAS} . c 0 m \% 20 \% 2 \mathrm{D} \% 20$ Seorang ,dan\%20rekening\%20ib\%20nya\%20kepada\%20polisi. Diakses pada April 2021.

Lewis, M., \& Slack, N. (2001). Operations Strategy ( $3^{\text {rd }}$ ed.). Harlow: Prentice-Hall. 


\section{Entrepreneurship Bisnis Manajemen Akuntansi (E-BISMA), 2(1), 18-26}

Bagaspati Atibrata Cahyolaksono, Adhitya Mahardhika, dan M. Ismail Zakaria

Kencana, M.R.B. (2021). OJK Akan Fokus Pada 6 Kebijakan untuk Tingkatkan Pengawasan Digitalisasi Keuangan. Tersedia di https://www.merdeka.com/uang/ojkakan-fokus-pada-6-kebijakan-untuk-tingkatkan-pengawasan-digitalisasikeuangan.html. Diakses pada Januari 2021.

Napitupulu. W.P. (2020). Gawat, 3000 Rekening Nasabah Dibobol oleh 10 Orang Sejak 2017. Tersedia di https://www.bukamata.co/berita/15056/gawat-3000-rekeningnasabah-dibobol-oleh-10-orang-sejak-2017/. Diakses pada April 2021.

Prambadi, G.A. (2021). Digitalisasi di Indonesia Dinilai Makin Merata. Tersedia di https://www.republika.co.id/berita/qq 0gb2456/digitalisasi-di-indonesia-dinilai-makinmerata. Diakses pada Januari 2021.

Republik Indonesia. Undang Undang Republik Indonesia tentang Perbankan. UU RI No 10 Tahun 1998

Sari, L. K. (2012). Penerapan manajemen risiko pada perbankan di Indonesia. Jurnal Akuntansi AKUNESA, 1(1), 1-21.

Sofyan, A. (2021). Perkembangan Digitalisasi di Indonesia. Tersedia di https://ezdigital.id/article/perkembangan-digitalisasi-di-indonesia. Diakses pada Maret 2021.

Supriyatna, I., dan Fauzi, A. (2020). OJK Ingatkan Lembaga Jasa Keuangan Mitigasi Risiko Digitalisasi Layanan. Tersedia di https://www.suara.com/bisnis/2020/12/11/071440/ ojk-ingatkan-lembaga-jasa-keuangan-mitigasi-risiko-digitalisasi-layanan?page=all. Diakses pada April 2021.

Tummala, R., \& Schoenherr, T. (2011). Assessing and managing risks using the Supply Chain Risk Management Process (SCRMP). Supply Chain Management: An International Journal, 16(6), 474-483. 